\title{
Um Ambiente para as Práticas Laboratoriais Remotas de Física: Estudo do Pêndulo Matemático
}

Title: An Environment for Remotes Laboratories Practices of Physics: A Study of the Mathematical Pendulum

\section{Vinícyus Santos Guimarães}

Faculdade de Tecnologia e Ciências (FTC)

vguimaraes.ti@gmail.com

Ivanor Nunes de Oliveira

Maísa Soares Santos Lopes

Universidade Estadual do Sudoeste da Bahia (UESB)

ivanor_nunes@hotmail.com

msslopes@gmail.com

\author{
Cláudio Rodolfo Sousa de Oliveira \\ Jeferson Alves Oliveira \\ Robson Mendes Reis \\ Instituto Federal de Educação, Ciência e Tecnologia \\ (IFBA) \\ claudiorodolfo@yahoo.com.br \\ jeferson.eng.elet@gmail.com \\ robsonmendes.r@hotmail.com
}

Resumo A utilização de novos recursos tecnológicos para as medições e elaboração dos dados de experimentos vem sendo observada nos últimos anos. Estes recursos são utilizados no âmbito da pesquisa científica, mas já estão sendo introduzidos também em práticas didáticas laboratoriais nas mais diversas áreas. O objetivo principal deste trabalho é apresentar os aspectos mais importantes para a prática laboratorial remota de física, visando disponibilizar ferramentas computacionais de ultima geração, aplicadas no ensino/aprendizagem. Neste contexto, o trabalho de laboratório que apresenta o estudo do pêndulo matemático a partir do modelo de laboratório remoto, será utilizado como estudo de caso para a validação da nova técnica de ensino/aprendizagem, em que o computador é utilizado em todo o âmbito da prática laboratorial. Com auxílio deste modelo, pretende-se: a) Estudar as oscilações de um pêndulo simples; b) Determinar as condições pelas quais um pêndulo pode ser considerado pêndulo matemático; c) Medir a aceleração da força de gravidade com o auxílio do pêndulo matemático automatizado. Pretende-se também, através da utilização do modelo de laboratório remoto, criar as condições para uma ligação efetiva entre teoria e experimento, permitindo a sua utilização nas modalidades de ensino presencial e à distância.

Palavras-Chave: Automatização. Laboratório remoto, Educação à Distância. Porta Paralela. Motor de Passo.

\begin{abstract}
The use of new technology to the measurements and preparation of experimental data has been observed in recent years. These resources are used in the context of scientific research, but are now also being introduced in laboratory teaching practices in several areas. The main objective of this paper is to present the most important aspects for remote laboratory practice in physics, aiming to provide computational tools of last generation, applied in teaching / learning. In this context, the laboratory work presents the study of the mathematical pendulum from the model of remote laboratory will be used as case study to validate the new technique of teaching / learning, in which the computer is used throughout the scope of laboratory practice. With the aid of this model, we intend to: a) study the oscillations of a simple pendulum, b) determine the conditions under which a pendulum may be considered mathematical pendulum c) Measure the acceleration of gravity with the aid of mathematical pendulum automated. It is also intended, through the use of remote laboratory model, create the conditions for an effective link between theory and experiment, allowing their use in methods of classroom teaching and distance.
\end{abstract}

Keywords: Automation. Remote Laboratory, Distance Education. Parallel Port. Stepper Motor. 


\section{Introdução}

As revoluções técnico-científicas na área de informática impõem a toda sociedade uma mudança de diversos paradigmas, dentre eles deve-se ressaltar a utilização de ferramentas computacionais para a coleta de dados das medições laboratoriais.

Durante a realização de um experimento num laboratório tradicional, o pesquisador tem acesso a uma gama de aparelhos específicos e também utiliza diversos instrumentos de medição para a determinação das grandezas de interesse no desenvolvimento de sua pesquisa. Neste contexto, o experimento depende muito da qualidade de sua atuação e em alguns experimentos, é desejável que um sistema computacional realize tarefas e procedimentos para minimizar possíveis falhas humanas. Em outros, a intervenção de equipamentos informatizados é indispensável, pois algumas experiências precisam ser realizadas em ambientes inadequados à presença humana.

Como se sabe, o experimento científico moderno é caracterizado por uma série de parâmetros mensuráveis, tornando-se fundamental a utilização do computador em diversos aspectos, como o controle e desenvolvimento do experimento, o registro e elaboração dos resultados das medições e a apresentação dos dados obtidos numa forma cômoda para o pesquisador. Atualmente, a utilização dos novos recursos tecnológicos para as medições e elaboração dos dados do experimento não está se restringindo somente à pesquisa científica, está sendo introduzida também nas práticas didáticas laboratoriais nas mais diversas áreas [1, 2, 3, 4].

O uso de laboratório, em cursos de ciências naturais, como física e química, e nas engenharias é essencial para formação profissional dos alunos. Entretanto, laboratório de pesquisa e ensino tem um custo financeiro alto no que diz respeito a sua montagem e manutenção. Uma alternativa é a utilização de laboratório remoto.

A expressão laboratório remoto é utilizada para definir experimento que é conduzido e controlado remotamente através da Internet. Nesse modelo, os experimentos utilizam componentes ou instrumentação reais em um local diferente de onde eles estão sendo manipulados. Esses laboratórios são adequados para Educação a Distância $(\mathrm{EaD})$, onde alunos e professores estão separados no espaço e/ou no tempo.

O desenvolvimento desses laboratórios é constituído de um conjunto de tecnologias de software e hardware que pode assumir as mais diversas configurações em função da escolha dos recursos tecnológicos empregados em sua implementação [5].
Neste trabalho, o estudo do pêndulo matemático caracteriza a introdução da informatização no Laboratório Didático de Mecânica da Universidade Estadual do Sudoeste da Bahia - UESB.

Verificou-se que, dentre os diversos experimentos utilizados como objeto de estudo, o pêndulo matemático apresenta diversas características importantes para a reutilização conceitual que, mais tarde, pode ser aplicada nos demais experimentos daquele laboratório.

O objetivo principal deste trabalho é apresentar os aspectos mais importantes para a prática laborarial remota de física, visando disponibilizar ferramentas computacionais de ultima geração, aplicadas no ensino/aprendizagem.

Nesse sentido, pretende-se, através do estudo do pêndulo matemático, criar as condições para projetar e implementar a base necessária para a informatização dos experimentos didáticos no Laboratório de Mecânica e, como consequência deste processo, fomentar a familiarização dos estudantes com as novas ferramentas computadorizadas e permitir sua inserção na era cibernética. Neste contexto, o pêndulo matemático insere-se no modelo de laboratório remoto e será utilizado como estudo de caso para a validação da nova técnica de ensino/aprendizagem, na qual o computador é utilizado em todo o âmbito da prática laboratorial.

As partes do trabalho estão organizadas da seguinte forma. A Seção 2 apresenta exemplos de trabalhos relacionados com o modelo de laboratório remoto. A Seção 3 apresenta um resumo da teoria do pêndulo matemático. A Seção 4 traz uma breve descrição acerca da maquete automatizada. A Seção 5 apresenta uma descrição acerca dos componentes responsáveis pelo funcionamento do experimento, tanto dos componentes físicos quanto da parte lógica. As funcionalidades do sistema são definidas na Seção 6, além de informações sobre as ferramentas utilizadas no desenvolvimento. A Seção 7 traz os resultados gerados a partir das experiências realizadas com o uso da maquete experimental. A Seção 8 finaliza o trabalho, trazendo as conclusões obtidas a partir do experimento, bem como sugestões para posteriores melhorias.

\section{Trabalhos Relacionados}

A literatura fornece vários exemplos de laboratórios remotos: [6] descreve o laboratório Michigan Ion Beam da Universidade de Michigan, onde é possível controlar e monitorar parâmetros de irradiação e parâmetros de fonte de íons remotamente; [7] descreve o desenvolvimento de um laboratório remoto de engenharia de controle que oferece aos alunos experiências com planta do mundo real interativa em controle e automação, resolução de problemas, coleta de dados e interpretação científica; Em [8], é apresentada a plataforma RMCLab (Remote Moni- 
tored and Controlled Laboratory) desenvolvida para experimentos de engenharia elétrica e tem com principal característica a utilização das experiências reais, em termos de instrumentação e circuitos sob medida; [9] fornece uma visão geral dos experimentos de medição disponíveis no laboratório didático remoto LA.DI.RE. "G. Savastano"; [10] apresenta a arquitetura de um laboratório remoto para o ensino de engenharia elétrica e utiliza como estudo de caso o experimento de controle de velocidade de quatro quadrantes para um motor de corrente contínua; [11] mostra a ferramenta desenvolvida para executar remotamente a medição da viscosidade de líquidos pelo método de Stokes, o trabalho descreve, além dos princípios físicos, o hardware e o software implementados para a experiência; [12] apresenta um laboratório remoto de processamento de sinal digital controlado por motor de indução; [13] mostra o funcionamento do módulo de controle de motores e os sensores de navegação inercial do $\pi$ bot, um pêndulo invertido que pode ser acessado remotamente.

Estudos realizados por [14 e 15] comparam a eficácia dos tradicionais laboratórios hand-on com laboratórios remotos e simulados, e concluem que as novas tecnologias podem ser usadas de forma eficaz em laboratórios de engenharia e de ciência para ensinar compreensão conceitual e habilidades profissionais.

Dessa forma, pretende-se, utilizando o modelo de laboratório remoto, criar as condições para uma ligação efetiva entre teoria e experimento permitindo a sua utilização nas modalidades de ensino presencial e à distância. Neste sentido, verifica-se que o surgimento do laboratório remoto está intrinsecamente ligado com as aplicações dos avanços da tecnologia da informação.

No presente experimento pretende-se: a) Estudar as oscilações de um pêndulo simples; b) Determinar as condições pelas quais um pêndulo pode ser considerado pêndulo matemático; c) Medir a aceleração da força de gravidade com o auxílio do pêndulo matemático automatizado.

\section{Estudo do Pêndulo Matemático}

Este trabalho está relacionado com o estudo do pêndulo matemático bifilar, utilizando o ambiente formado pela maquete experimental automatizada do referido pêndulo, projetada e desenvolvida no Laboratório de Mecânica da UESB, controlada por meio de um computador. A maquete é constituída por sistemas movidos por motores de passo que permitem a definição dos parâmetros do pêndulo, um circuito eletrônico para o seu acionamento e um software que controla o circuito, possibilitando a manipulação dessa maquete, remotamente, para a prática laboratorial nas modalidades de ensino presencial e à distância.
Chama-se pêndulo matemático um sistema idealizado constituído por uma linha imponderável e inelástica na qual está suspensa uma massa pontual, que oscila no campo gravitacional da Terra. Entretanto, uma boa aproximação, deste conceito ideal, é obtida com a utilização de uma pequena esfera metálica suspensa por uma linha fina, cujo comprimento deve ser muito maior que 10 vezes o raio da esfera. A Figura 1 representa o pêndulo matemático. Nela estão representadas as seguintes grandezas físicas: 1 - comprimento do fio de suspensão do pêndulo; $\varphi$ - ângulo de inclinação do pêndulo; $\mathrm{x}$ - desvio do pêndulo da posição de equilíbrio; $\vec{F}_{T}$ - força de tração da linha de suspensão; $\mathrm{m} \vec{g}$ - força de gravidade; $\vec{F}_{R}$ força resultante [16].

\subsection{Descrição do Movimento do Pêndulo}

A dedução da equação do movimento oscilatório do pêndulo, representado na Figura 1, pode ser realizada utilizando a segunda lei de Newton. Esta pode ser escrita da maneira expressa na seguinte equação:

$$
\ddot{x}+\omega_{o}^{2} x=0 \text {. }
$$

A solução desta equação tem a forma

$$
x=A \cos \left(\omega_{o} t+\varphi_{o}\right),
$$

onde $A$ e $\varphi_{o}$ são constantes. A grandeza $A$ do desvio máximo da posição de equilíbrio chama-se amplitude das oscilações, $\omega_{o} t+\varphi_{o}$ é a fase, e $\varphi_{o}$ é a fase inicial. As grandezas $A$ e $\varphi_{o}$ são determinadas pelas condições iniciais das oscilações.

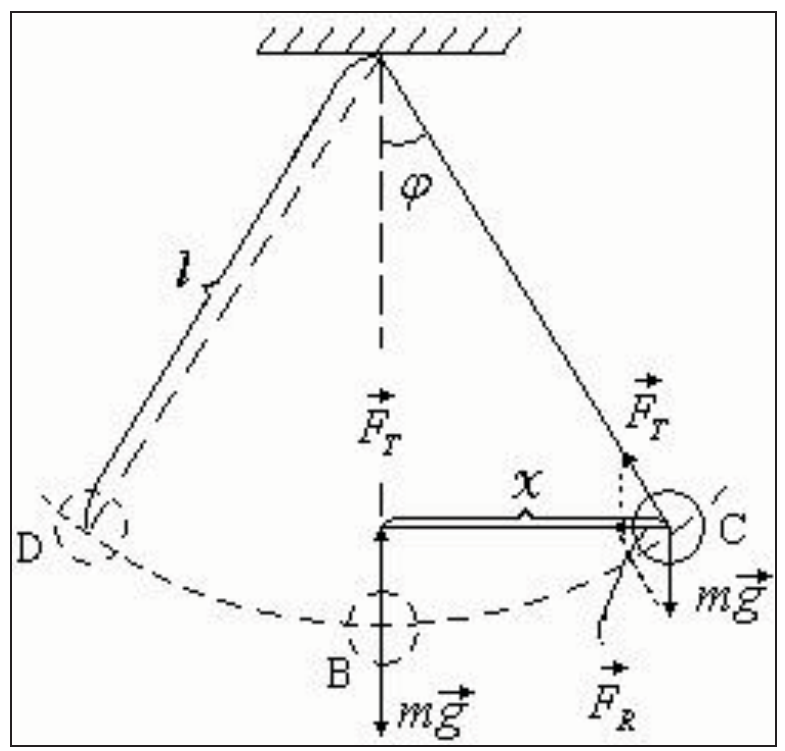


Figura 1 : Pêndulo matemático e suas grandezas físicas.

Como $\cos \left(\omega_{o} t+\varphi_{o}\right)$ é uma função periódica, então no decorrer do tempo $t=T_{o}$ a fase recebe um incremento de $2 \pi$ e o pêndulo volta à posição inicial, conservando o sentido inicial do movimento e realizando um ciclo completo de oscilações. O intervalo de tempo $T_{o}$ chama-se período das oscilações e $\omega_{o}$ frequência cíclica das oscilações próprias (harmônicas) do pêndulo.

Tendo-se em conta a ligação entre $T_{o}$ e $\omega_{o}$, a expressão para o período das oscilações próprias do pêndulo pode ser escrita da seguinte forma:

$$
T_{o}=2 \pi \sqrt{\frac{l}{g}} .
$$

Desta expressão vê-se que $T_{o}$ não depende nem da massa $m$ do pêndulo nem da amplitude $A$ das oscilações. As oscilações cujo período não depende da amplitude são chamadas isocrônicas.

Somente um pêndulo matemático idealizado, que oscile com um ângulo de inclinação $\varphi$ pequeno, possui as propriedades descritas acima.

Se a comprovação experimental mostrar que se cumprem as condições pelas quais o pêndulo utilizado no trabalho de laboratório possa ser considerado pêndulo matemático, então, da expressão (3), é possível obter uma expressão simples para a determinação do valor da aceleração da força de gravidade apresentada abaixo:

$$
g=\frac{4 \pi^{2} l}{T_{o}^{2}} .
$$

\subsection{Condições de aplicação do método do pêndulo matemático}

Chama-se pêndulo físico qualquer corpo sólido que oscila em torno de um eixo horizontal fixo que não passa pelo seu centro de gravidade. Um exemplo simples de tal pêndulo é uma esfera de certo raio $R$, suspensa por uma linha inelástica, imponderável, de comprimento $l$, como pode ser visto na Figura 2 .

A condição de inelasticidade da linha de suspensão da esfera foi adicionada para simplificar o caráter da oscilação do pêndulo, para desprezar a deformação do comprimento da linha e as consequências decorrentes desta deformação.

A teoria permite deduzir a equação do movimento oscilatório do pêndulo físico utilizando diferentes métodos.
Aqui, vamos utilizar a lei fundamental da dinâmica do movimento de rotação. Esta equação tem a forma:

$$
I \varepsilon=\sum M_{i}
$$

onde $I$ é o momento de inércia do pêndulo, $\varepsilon=\ddot{\varphi}$ a sua aceleração angular, $\sum M_{i}$ a soma dos momentos de todas as forças que atuam no pêndulo.

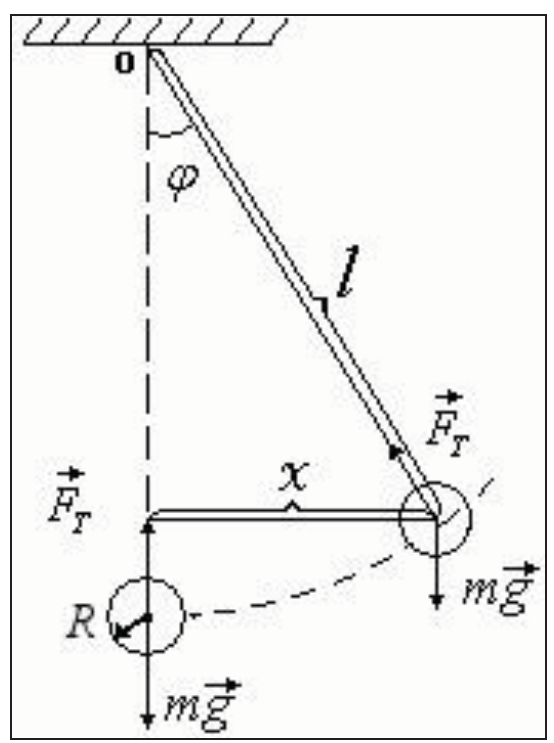

Figura 2 : Pêndulo físico e forças atuantes.

Depois de algumas considerações, obtém-se a seguinte equação do movimento oscilatório do pêndulo físico

$$
\ddot{\varphi}+\omega_{o}^{2} \varphi=0,
$$

que coincide pela forma com a equação (1), se for escrita a substituição $x \rightarrow \varphi$.

A solução da equação (6) tem o aspecto semelhante a equação (2)

$$
\varphi=\varphi_{o} \cos \left(\omega_{o} t+\vartheta_{o}\right)
$$

e descreve oscilações próprias do pêndulo físico com período

$$
T_{o}=2 \pi \sqrt{\frac{I}{m g l}} .
$$

O momento de inércia $I$ do pêndulo, representado na Figura 2, pode ser encontrado pelo teorema de Steiner. Entretanto, se for cumprida a relação $R<<l$, então a expressão para o momento de inércia toma o aspecto: 


$$
I \approx m l^{2}
$$

Substituindo-se a expressão (9) na equação (8), obtemos uma fórmula que coincide com a fórmula (3) para o período das oscilações próprias do pêndulo matemático.

\section{Maquete Experimental}

A maquete experimental do pêndulo matemático contém os recursos necessários para ser operada de forma automatizada e controlada por sistemas computacionais. Sua estrutura básica é apresentada na Figura 3, que mostra, entre os demais componentes, a base metálica e o suporte vertical do pêndulo matemático bifilar.

Esta maquete é composta pelos seguintes sistemas. I) Sistema de posicionamento $Y$ : formado por duas barras cilíndricas que servem de guia do movimento vertical da plataforma (6) com o auxílio de um fuso movido pelo motor de passos (1). A plataforma contém uma alavanca, controlada por um motor de passos, formando uma gaveta, que prende e libera a esfera em dada posição para o início das oscilações próprias do pêndulo e a realização da captura dos períodos do movimento oscilatório. II) Sistema de deslocamento linear $X$ : composto por dois trilhos para o movimento do carrinho (3), que serve de base para o sistema de posicionamento $\mathrm{Y}$. A movimentação horizontal do carrinho é realizada com o auxílio do motor de passos (2). III) Sistema de troca de esferas: composto por uma bandeja (5), que contem as esferas organizadas por ordem crescente das suas massas. A bandeja é guiada sobre dois eixos paralelos fixos que garantem a sua movimentação linear com o auxílio do motor de passo (4) que controla o deslocamento do sistema. IV) Sistema de regulagem do comprimento da linha bifilar (11), que sustenta a esfera durante o movimento oscilatório: composto por um motor de passos (8) que gira um eixo com os dois carretéis (7), onde as linhas são enroladas. O sistema mantém a esfera sempre centrada, condição necessária para efetuar a troca automática das esferas e garantir que o seu movimento ocorra sempre no mesmo plano. V) Sistema de captura dos períodos: basicamente formado por um sensor que controla a captura dos períodos. O mesmo está representado em (9).

O circuito eletrônico (10) foi projetado e construído utilizando-se o microcontrolador PIC, que controla sensores, motores de passos para o monitoramento e manipulação da maquete experimental do pêndulo matemático, comunica-se com o computador através da porta paralela, com o objetivo da automatização do experimento.

\section{Automatização da Maquete Experi- mental}

Neste tópico, serão abordados o hardware e o software de controle da maquete experimental do pêndulo ma- temático. Isto inclui a abordagem da utilização da porta paralela, dos princípios de funcionamento dos motores de passos e seus drivers, dos circuitos eletrônicos e dos sensores utilizados, e a descrição dos movimentos necessários para a realização do experimento.

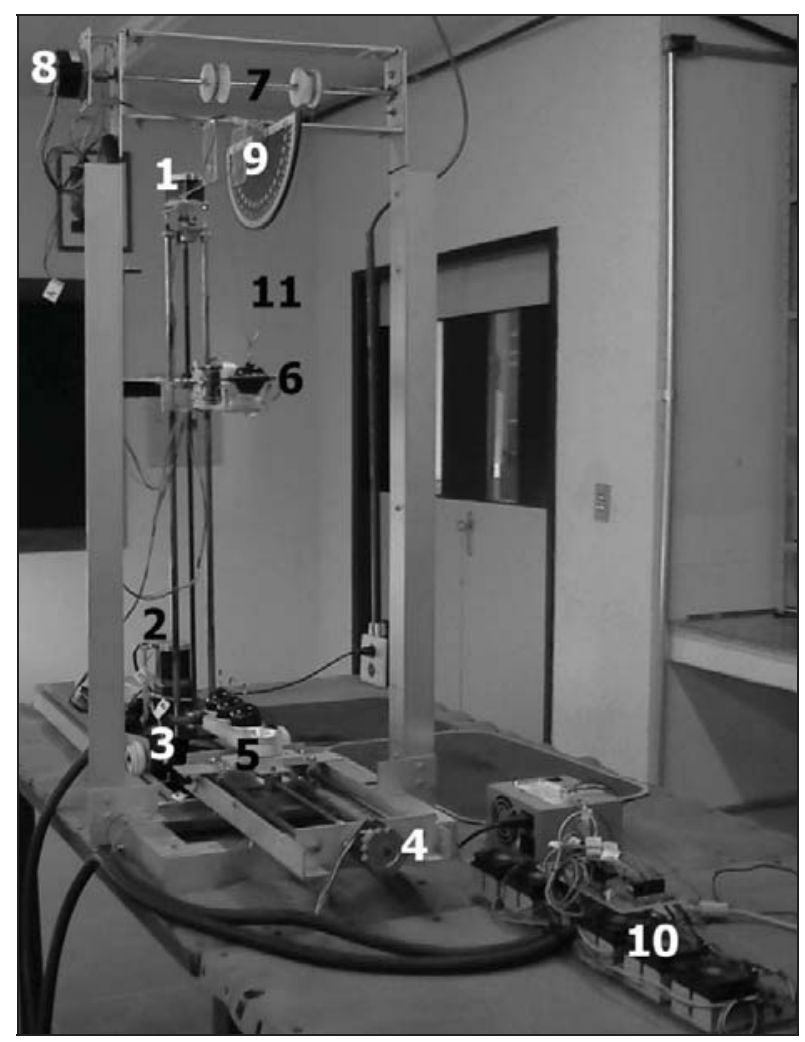

Figura 3 : Maquete Experimental do Pêndulo Matemático.

\subsection{Interface de Comunicação Paralela}

O nome padrão da porta paralela é o Line Print Terminal (LPT), seguida de um número referente a quantidade de portas disponíveis no dispositivo, como por exemplo LPT1. O endereço base para acesso a essa interface pode ser encontrado no Setup da máquina e usualmente é dado por: $0 x 378$ (em notação hexadecimal ou $888 \mathrm{em}$ decimal), para o envio de um byte de dados à porta; $0 \times 379$, para receber um valor por meio da porta; e $0 \times 37 \mathrm{~A}$, para o envio de dados de controle.

Os pinos da porta estão em nível lógico 0 quando a tensão elétrica do mesmo está entre 0 e $0,4 \mathrm{v}$. Quando um pino está no nível lógico 1 , a tensão elétrica do mesmo varia entre 3,1 e $5 \mathrm{v}$. Os valores dos níveis lógicos são invertidos em alguns pinos do registro de controle [17].

A porta paralela contém 25 pinos, e pode operar com 7 transmissão unidirecional "SPP" ou bidirecional "EPP" ou "ECP". Os pinos 2 ao 9 controlam o registro de dados. Os pinos do registro de controle são: Select In (17), Init (16), Auto Feed (14), e Strobe (1). Já os pinos do registro 
de status são: Acknowledge (10), Busy (11), Paper End (12), Select Out (13) e Error (15). Os demais pinos são de aterramento.

Três dos quatro pinos de controle trabalham de forma invertida, ou seja, quando a tensão elétrica no pino está baixa $(0-0,4 \mathrm{v})$, ele se encontra no nível lógico 1 , e com tensão alta $(3,1-5 \mathrm{v})$, nível lógico 0 . Somente o pino Init (16) trabalha na sua forma normal

Para a automatização do experimento, foi necessário utilizar todos os pinos do registro de dados, além dos pinos Auto Feed (14) e Init (16) do registro de controle, e assim controlar os cinco motores de passo presentes na maquete. Já para a captura dos períodos, foi utilizado o pino Error (15) do registro de status.

\subsection{Motores de Passo}

Os motores de passo são, basicamente, os principais responsáveis por toda a movimentação do experimento.

A denominação dos motores, segundo a pinagem da porta paralela usada para o controle, ficou definida como expresso na Tabela 1.

\begin{tabular}{c|c|c}
\hline Nome & Descrição & $\begin{array}{c}\text { Pinos Utilizados } \\
\text { (Número) }\end{array}$ \\
\hline $\begin{array}{c}\text { Motor 1 } \\
\text { (M1) }\end{array}$ & $\begin{array}{c}\text { Controla a abertura e o } \\
\text { fechamento da gaveta. }\end{array}$ & Init (16) - D0 (2) \\
\hline $\begin{array}{c}\text { Motor 2 } \\
\text { (M2) }\end{array}$ & $\begin{array}{c}\text { Controla o comprimento } \\
\text { da linha de suspensão. }\end{array}$ & D2 (4) - D1 (3) \\
\hline $\begin{array}{c}\text { Motor 3 } \\
\text { (M3) }\end{array}$ & Controla o Eixo X. & D4 (6) - D3 (5) \\
\hline $\begin{array}{c}\text { Motor 4 } \\
\text { (M4) }\end{array}$ & Controla o Eixo Y. & D6 (8) - D5 (7) \\
\hline $\begin{array}{c}\text { Motor 5 } \\
\text { (M5) }\end{array}$ & $\begin{array}{c}\text { Controla a } \\
\text { banimentação da }\end{array}$ & $\begin{array}{c}\text { Auto Feed (14) - } \\
\text { D7 (9) }\end{array}$ \\
\hline
\end{tabular}

Tabela 1 : Denominação dos Motores de Passo e Pinagem utilizada para controle da Maquete Experimental.

São necessários 200 passos para que uma volta completa seja dada no eixo dos motores de passo usados na maquete. Cada passo movimenta portanto 1,8 graus. Todos os motores são iguais.

Para que o carrinho que retém a esfera e coordena o eixo $X$ ande $1 \mathrm{~mm}$, é necessário dar aproximadamente 19,230 passos no motor. São necessários 133,333 passos no motor que coordena o eixo $Y$ para percorrer a mesma distância, uma vez que os sistemas de engrenagens utilizados para redução, são diferentes. Este mesmo valor é o necessário para movimentar essa mesma distância a bandeja das esferas. Para que a movimentação seja efetuada com precisão, a quantidade de passos é multiplicada pela diferença entre o espaço final e o inicial, em milímetros. Logo após, o valor é arredondado, pois a quantidade final de passos a ser executada deve conter um valor inteiro.

Cada motor de passo utiliza dois pinos da porta paralela para prover a movimentação. Um pino é responsável pelo sentido (horário/anti-horário) no qual o motor irá girar, e o outro é o STEP (um passo). Quando o pino responsável pelo sentido encontra-se com o nível lógico baixo gira para um lado, e com o nível lógico alto, gira para outro. Para que haja a movimentação, é necessário que haja um pulso elétrico no motor, isto é conseguido escrevendo na porta de maneira que este pino receba num momento o comando para nível lógico alto, logo depois, um comando para nível lógico baixo, e deve-se haver um tempo de espera igualmente determinado entre estes comandos, provendo uma movimentação uniforme do motor de passo. Quanto menor for este tempo de espera, mais rápido o motor trabalha, entretanto há um tempo mínimo dado pelas características inerciais do sistema o qual deve ser obedecido. Sendo assim, para um passo completo no motor, é necessário escrever nos pinos, dar um tempo de espera, escrever novamente, e depois dar o mesmo tempo de espera.

Para controlar os Motores 1 e 5, é necessário escrever simultaneamente em pinos de dados e de controle. Para tal, necessita-se escrever nos endereços individualmente, dar o tempo de espera, escrever novamente individualmente, e dar o mesmo tempo de espera.

\subsection{Sensores da Maquete}

A maquete automatizada utiliza sete sensores: um é utilizado na captura dos períodos durante o movimento oscilatório, enquanto os outros verificam a posição da esfera antes, durante e após a execução do experimento. É utilizado o método read() e write(), da API Parport, utilizada para ler e escrever valores inteiros na porta paralela, via um programa desenvolvido na linguagem de programação Java. São utilizados os pinos Ack (10), Busy (11), Paper End (12), Select Out (13) e Error (15).

A fim de assegurar que a esfera esteja na posição inicial no momento da execução, foram necessários instalar sensores de movimento em cada um dos motores da maquete (vide Tabela 2).

Os sensores 1, 5 e 7 (Tabela 2) compartilham o mesmo pino de entrada. Para isso, foi necessário utilizar um microcontrolador e dois pinos de controle (Strob (1) e Select In (17)), em que, para se obter o sinal de um dos sensores, deve-se enviar para os mesmos o valor lógico correspondente.

Antes da execução do experimento, é verificado o sinal lógico que cada sensor está enviando, e se algum destes indicar que não está na posição inicial, automaticamente, o programa de controle da maquete inicializa a busca da posição correta. Estes sensores são fundamentais, pois corrigem a posição da maquete e garantem a 
continuidade da realização dos experimentos, mesmo após algum erro de execução ou uma possível queda de energia.

\begin{tabular}{|c|c|c|}
\hline $\begin{array}{l}\mathrm{N}^{0} \text { do } \\
\text { Sensor }\end{array}$ & Descrição & $\begin{array}{c}\text { Pino } \\
\text { Utilizado }\end{array}$ \\
\hline 1 & Sensor da bandeja das esferas & Busy (11) \\
\hline 2 & $\begin{array}{c}\text { Sensor Horizontal do Carrinho - } \\
\text { Eixo X }\end{array}$ & $\begin{array}{l}\text { Paper End } \\
\text { (12) }\end{array}$ \\
\hline 3 & $\begin{array}{c}\text { Sensor Vertical do Carrinho - } \\
\text { Eixo Y }\end{array}$ & $\begin{array}{l}\text { Select Out } \\
\text { (13) }\end{array}$ \\
\hline 4 & Sensor de Controle da Linha & Ack (10) \\
\hline 5 & Sensor de Abertura da Gaveta & Busy (11) \\
\hline 6 & Sensor de Captura dos Períodos & Error (15) \\
\hline 7 & Sensor da Posição da Bola & Busy (11) \\
\hline
\end{tabular}

Tabela 2 : Classificação dos Sensores da Maquete Automatizada.

Durante o período de oscilação, o sinal de entrada que capta a passagem do pêndulo, sensor de número 6 , fica no nível lógico baixo, e no momento em que a linha intercepta este sensor, é enviado um sinal de nível lógico alto para o pino de entrada correspondente. No programa, a função de captura utiliza um laço, que a cada 1 milissegundo lê a porta, trabalhando como uma espécie de cronômetro. Quando a linha, do pêndulo, intercepta o sensor, a porta envia um valor diferente, e assim é possível definir os períodos com precisão.

Ao término da contagem do número definido de ciclos do movimento oscilatório, os sensores de posição são verificados para garantir que a maquete esteja situada novamente na sua posição de origem e pronta para a próxima execução.

\subsection{Software de Controle}

O Software de Controle consiste, basicamente, no estudo da dependência do período de oscilações da massa, do ângulo de inclinação e do comprimento da linha de suspensão.

A equação da circunferência é essencial para levar a esfera até a posição desejada, e para que possam ser capturados os períodos com exatidão. Ela pode ser escrita na seguinte forma:

$$
Y=\sqrt{R^{2}-X^{2}}
$$

A posição inicial, com a esfera em repouso, pode ter seu ponto $(X, Y)$ definido como $(0,-R)$, considerando que a operação será efetuada no quarto quadrante, e $R$ é o raio do círculo, que no caso do experimento, pode ser representado pelo comprimento da linha de suspensão.

Foram definidos incrementos de $5 \mathrm{~mm}$ em $X$, e após cada um, a equação paramétrica é aplicada. A diferença entre o valor antigo de $Y$, e o novo, determinado após cada cálculo da equação, é o incremento de $Y$. A implementação desta função, utilizando a linguagem de programação Java, foi possível com o uso do método Math.sqrt(), utilizado para determinar a raiz quadrada.

Para se chegar, por exemplo, ao ângulo de 10 graus, é necessário definir quantos incrementos serão necessários para tal. A solução, neste caso, foi a de encontrar o espaço final de $X$, em milímetros, dividindo por 5, que é o espaço que cada incremento em $X$ percorre, resultando na quantidade de incrementos que serão necessários para se chegar ao espaço final. Isso foi possível utilizando a equação:

$$
Z=\operatorname{sen} \theta \cdot R
$$

Nessa equação, $Z$ representa o espaço final de $X$. No Java, é possível determinar o valor do seno de um determinado ângulo $\theta$ utilizando o método Math.sin(), que recebe o valor do ângulo em radianos. Este por sua vez pode ser convertido de graus para radianos utilizando-se o método Math.toRadians(). $R$ representa o raio do círculo, por sua vez representado pelo comprimento da linha, em milímetros.

\subsection{Configuração dos Experimentos}

Para o primeiro experimento, que consiste em estudar a dependência do período das oscilações da massa da esfera, são utilizadas quatro esferas com massas de 164,19, 192,97, 200, 201,46 e 221,40 g, respectivamente. Para o segundo experimento, que consiste da determinação do intervalo de valores de amplitudes nos limites nos quais se conserva a isocronia das oscilações, foram escolhidos os ângulos de: $4^{\circ}, 7^{\circ}, 10^{\circ}, 20^{\circ}, 30^{\circ}$ e $40^{\circ}$. Por último, para o estudo da dependência do período de oscilações do pêndulo do comprimento de linha de suspensão (terceiro experimento), foram escolhidos os seguintes comprimentos de linha: 785, 646, 512, 374 e $232 \mathrm{~mm}$. O número de ciclos a serem capturados ficou definido em 10 períodos.

As etapas do primeiro experimento foram definidas da seguinte maneira. Com a primeira esfera suspensa dentro da gaveta, inicia-se o processo para levá-la até a posição de soltura, referente ao ângulo de 7 graus. Esta posição corresponde ao ponto definido pelas coordenadas $x$ e $y$, obtidas com a utilização dos sistemas de posiciomentos $X$ - $Y$, com o auxílio da equação paramétrica do círculo. Chegando à posição de soltura, a gaveta é aberta liberando a esfera, que começa a oscilar. Quando a linha de suspensão da esfera corta pela primeira vez o sensor de captura, é iniciado o temporizador que, por sua vez, capturará dez períodos. Terminada a captura de dez períodos, a gaveta é levada até a posição inicial, amortecendo as oscilações do pêndulo até a parada da esfera na posição de equilíbrio. Nesse momento, a gaveta é fechada. Este procedimento se repete cinco vezes com cada uma das 
quatro esferas. Logo após o quinto procedimento, a gaveta é aberta e o carinho 3 é deslocado de $70 \mathrm{~mm}$ em relação à posição da bandeja de esferas. Variando-se, adequadamente, o comprimento da linha de suspensão da esfera do pêndulo, esta é colocada no seu lugar de origem sobre a bandeja e a linha de suspensão libera-se do gancho preso à esfera. Em seguida, a bandeja, é deslocada de $15 \mathrm{~mm}$ para trás e a linha de suspensão é elevada para que a bandeja seja deslocada de $60 \mathrm{~mm}$ para frente. Feito isso, a linha desce novamente para que possa pegar a segunda esfera. A bandeja desloca-se $15 \mathrm{~mm}$ para frente e, assim, a linha entra no gancho. Logo, em seguida, a esfera é erguida até a posição inicial, o carrinho 3 desloca-se 70 $\mathrm{mm}$ para frente, para que a gaveta se posicione sob a esfera, quando esta é fechada. O mesmo procedimento feito com a primeira esfera é repetido com a segunda esfera e também com as demais esferas. Após a realização do procedimento com a última esfera, a mesma é deixada na bandeja e a linha é suspensa, novamente, para que a bandeja desloque-se para trás $180 \mathrm{~mm}$. A linha desce, novamente, diante da primeira esfera e a bandeja desloca-se $15 \mathrm{~mm}$ para frente para que a linha entre no gancho da esfera e esta seja suspensa até a posição inicial e o primeiro experimento possa ser finalizado.

No segundo experimento, o estudo da dependência do período das oscilações do ângulo de inclinação do pêndulo começa com o ângulo de $4^{\circ}$, mantendo-se constantes a massa da esfera e o comprimento da linha de suspensão. Captura-se o tempo de dez oscilações do pêndulo . Esse procedimento é repetido cinco vezes para os ângulos de $7^{\circ}, 10^{\circ}, 20^{\circ}, 30^{\circ}$ e $40^{\circ}$ utilizando-se os sistemas de posicionamento $X-Y$ e a equação paramétrica do círculo para a obtenção do ponto de soltura da esfera correspondente a cada ângulo.

No terceiro Experimento, os parâmetros do pêndulo são a massa ( qualquer massa do conjunto utilizado ) e o ângulo de inclinação igual a $7^{\circ}$, sendo que a variável é o comprimento da linha de suspensão. Foram escolhidos cinco comprimentos da linha, obtidos com o auxílio do sistema de regulagem do comprimento da linha de suspensão da esfera do pêndulo. Após cada encurtamento da linha, o sistema de posicionamento $Y$, leva a plataforma (6), com gaveta fechada, ao encontro da esfera suspensa. Esse sistema, juntamente com o sistema de deslocamento linear $X$, com o auxílio da equação paramétrica do círculo, posiciona a esfera no ponto de soltura, onde a inclinação é de $7^{\circ}$. Com a abertura da gaveta, a esfera é solta e inicia-se o movimento oscilatório do pêndulo. Realiza-se a captura de dez períodos das oscilações. Como nos casos anteriores, com o auxílio dos sistemas $X-Y$, o pêndulo é levado até a posição de equilíbrio, a gaveta é fechada e todo o processo é realizado, novamente, cinco vezes.

\section{Sistema Web para Manipulação}

\section{Remota da Maquete}

Neste tópico, falar-se-á sobre o gerenciamento e a utilização do sistema, funcionalidades e metodologias utilizadas, além dos meios utilizados no armazenamento de dados.

\subsection{Funcionalidades do Sistema}

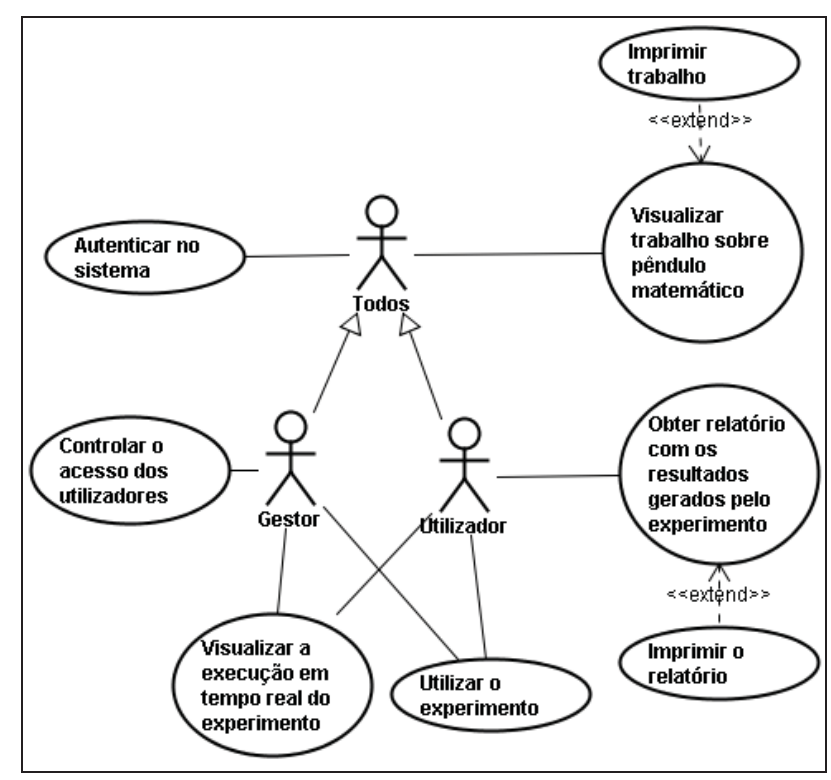

Figura 4 : Diagrama de Casos de Uso do Sistema Web.

Nesta parte, apresentamos as funções básicas da maquete experimental do pêndulo matemático, e a sua relação com os usuários.

A Figura 4 apresenta um diagrama de Casos de Uso da Unified Modelling Language (UML) contendo as funcionalidades do sistema.

O ator denominado "Todos" representa qualquer pessoa que venha a acessar a página do projeto. É permitido visualizar e imprimir o texto do trabalho de laboratório proposto.

O ator "Utilizador" pode realizar as funções necessárias para obter os resultados do sistema do pêndulo matemático, que são a realização e a visualização do experimento, e a posterior geração do relatório final. Utilizando login e senha, o aluno tem acesso à tela principal do sistema do pêndulo matemático, e por meio desta é possível verificar os resultados de cada experiência realizada, acionar a maquete para uma nova medição (ou seguir alguma execução caso a maquete esteja em andamento). Se o aluno já realizou os três experimentos disponíveis, o mesmo pode obter um relatório completo contendo os resultados das últimas execuções que acompanhou.

É possível que mais de um utilizador acompanhe o 
experimento ao mesmo tempo. Todos têm acesso ao mesmo resultado após a execução.

O ator "Gestor" tem a função de controlar o acesso de usuários ao sistema. Existe um cadastro, no qual é possível inserir novos usuários, editar os dados dos mesmos, além da possibilidade de bloqueio de acesso ao sistema. Este também pode utilizar o experimento, além de visualizar a execução do mesmo em tempo real.
Os atores "Gestor" e "Utilizador" têm acesso ao sistema mediante a prévia autenticação dos mesmos, com o uso de login e senha, definidos no momento do cadastro dos dados de cada um.

A Figura 5 apresenta o diagrama de classes do sistema do pêndulo matemático automatizado.

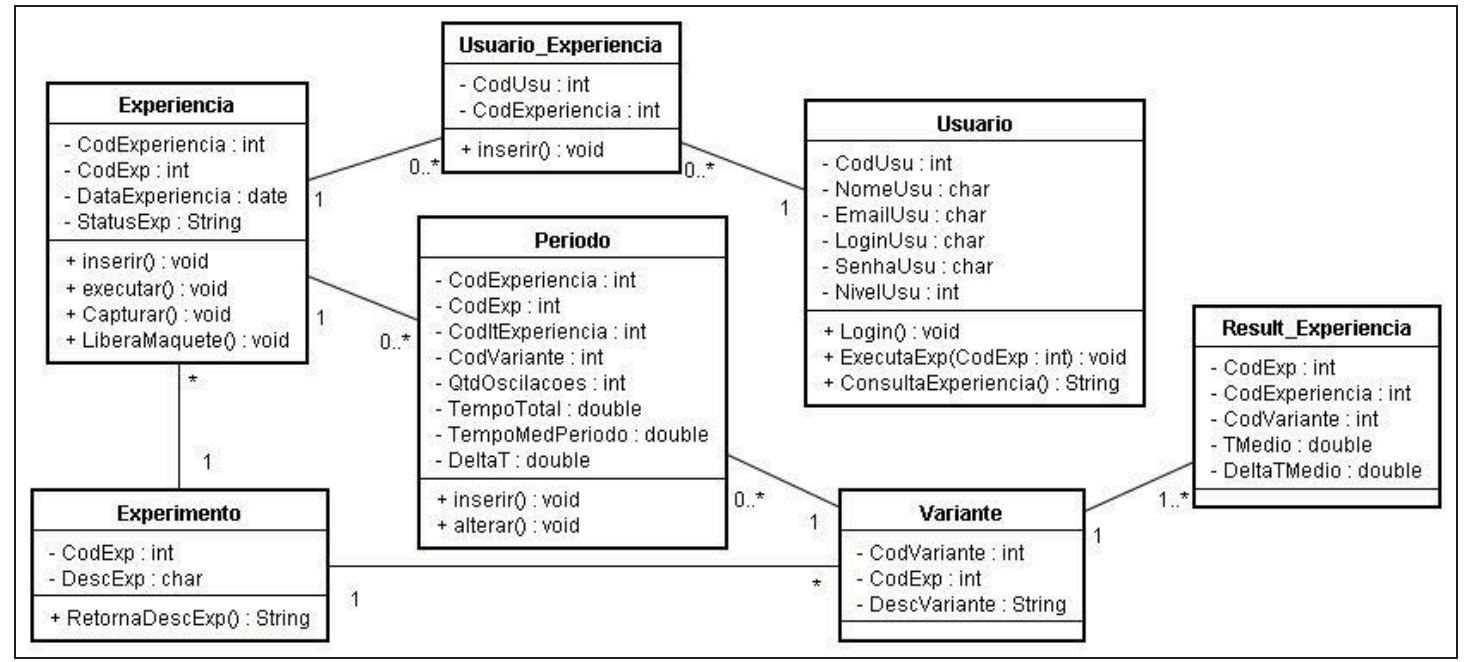

Figura 5 : Diagrama de classes do Pêndulo Matemático automatizado.

\subsection{Transmissão de Vídeo}

Para a disponibilização das imagens do experimento em tempo real, está sendo utilizada uma ferramenta denominada Yawcam (Yet Another Webcam Software). A mesma foi desenvolvida na linguagem de programação Java, e disponibiliza vários recursos para a transmissão de imagens, e dentre estes, o que está sendo utilizado no experimento é o de stream de vídeo. A ferramenta oferece uma interface gráfica bastante simples de se utilizar, e por meio desta é possível configurar alguns detalhes no oferecimento do vídeo. É possível disponibilizar o serviço utilizando qualquer porta, mas a escolhida para a transmissão das imagens em tempo real do experimento foi a 2510 .

A configuração foi efetuada para que possam ser transmitidas imagens a 15 frames por segundo, que é uma qualidade de $50 \%$ do máximo permitido. Estes valores foram definidos a fim de minimizar travamentos e atrasos durante a transmissão da execução do experimento.

\subsection{Páginas Web}

A ferramenta é dividida em duas partes. Uma é a parte do cliente, desenvolvida em JavaServer Pages (JSP) 2.0, e a segunda é a parte do servidor, desenvolvida em Java Standard Edition (JSE) 6.0.
A ferramenta responsável por disponibilizar ao usuário toda a movimentação da maquete, além da obtenção e visualização dos resultados, é denominada Apache Tomcat 6.0. A porta utilizada é a padrão para sistemas web, ou seja, porta 80 .

No lado do cliente (client-side) foi desenvolvida a interface de comunicação entre o sistema e os usuários (aluno, administrador, todos). Para o desenvolvimento, foram utilizados: HyperText Markup Language (HTML), para o conteúdo, Javascript para validação dos formulários, Cascading Style Sheets (CSS), para estilização da tela, e JSP para gerenciar as funcionalidades. A partir deste, é possível acessar o stream de vídeo, que mostra em tempo real a execução do experimento. A Figura 6 mostra a tela inicial da interface web, disponibilizada ao aluno no momento em que o mesmo acessa a página.

A comunicação entre o cliente e o servidor é feita por meio do uso de Web Services, que possibilita receber informações expressas na linguagem eXtensible Markup Language (XML). Para isso fez-se o uso de uma ferramenta denominada Apache Axis 1.4, que faz a conversão de chamadas de funções em Java, para informações textuais expressas em XML. Esta ferramenta é bastante utilizada, e é um produto de distribuição gratuita.

O sistema cliente recebe as informações do sistema 
servidor e as disponibiliza na tela ou num relatório, além de armazenar as mesmas num banco de dados, para acesso posterior às informações.

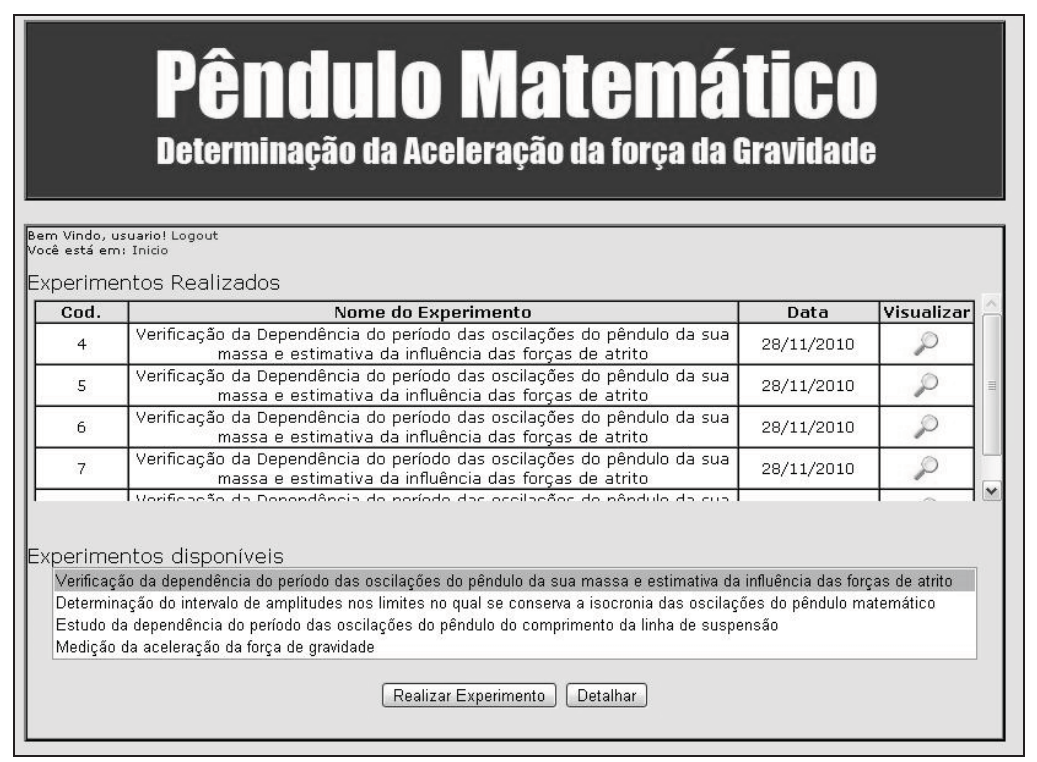

Figura 6 : Tela principal da interface web

A Figura 8 contém a página principal, que é mostrada ao usuário, após autenticar-se no sistema. Todas as funcionalidades que podem ser usadas pelos alunos são descritas no manual do aluno.

O lado do Servidor (server-side) é responsável por captar as informações solicitadas pelos usuários na interface web, enviar os comandos via porta paralela, receber os dados via a mesma porta, tratá-los (realizar os devidos cálculos), devolver as informações ao sistema cliente via Apache Axis.

A comunicação entre os sistemas cliente e servidor é composta de várias funções, que a depender podem realizar procedimentos, como o acionamento da maquete, ou simplesmente retornar informações, como os dados de uma experiência realizada. Quando o mesmo faz uma requisição, o serviço emite o retorno no formato XML. O cliente recebe o dado, interpreta-o e retorna na tela para o usuário.

\section{Resultados do Experimento}

A maquete experimental automatizada do pêndulo simples permitiu a realização de três experimentos: 1) Estudo da dependência do período das oscilações de diferente massas de um conjunto de esferas; 2) Estudo da dependência do período das amplitudes das oscilações; 3) Estudo da dependência do período das oscilações dos comprimentos da linha de suspensão da esfera do pêndu- lo. A partir dos dados obtidos de cada experimento, é montada uma tabela e construído o respectivo gráfico. As tabelas são criadas a partir da linguagem HTML e disponibilizadas na tela do usuário. Já os gráficos são obtidos por meio de uma ferramenta denominada Cewolf, que também possui distribuição gratuita, além de ser open source (contém os códigos-fonte abertos). A seguir, apresentamos resultados obtidos nos experimentos realizados.

Com base no Primeiro experimento, foi gerada a Figura 7 .

\begin{tabular}{|c|c|c|c|c|c|}
\hline \multirow{2}{*}{$m[g]$} & \multirow{2}{*}{\multicolumn{5}{|c|}{ 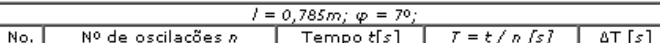 }} \\
\hline & & No de oscilaçöes $n$ & Tempot $[s]$ & $T=t / n[s]$ & $\Delta \mathrm{T}[s]$ \\
\hline $164,19 \mathrm{~g}$ & $\begin{array}{l}1 \\
2 \\
3 \\
4 \\
5\end{array}$ & 10 & $\begin{array}{l}17.891 \\
17.875 \\
17.89 \\
17.891 \\
17.891\end{array}$ & $\begin{array}{l}1.789 \\
1.788 \\
1.789 \\
1.789 \\
1.789 \\
\end{array}$ & $\begin{array}{l}0.0010 \\
0.0010 \\
0.0010 \\
0.0010 \\
0.0010 \\
\end{array}$ \\
\hline $192,97 \mathrm{~g}$ & $\begin{array}{l}1 \\
2 \\
3 \\
4 \\
5\end{array}$ & 10 & $\begin{array}{l}17.875 \\
17.875 \\
17.891 \\
17.875 \\
17.875\end{array}$ & $\begin{array}{l}1.788 \\
1.788 \\
1.789 \\
1.788 \\
1.788 \\
\end{array}$ & $\begin{array}{l}0.0010 \\
0.0010 \\
0.0010 \\
0.0010 \\
0.0010\end{array}$ \\
\hline $201,46 \mathrm{~g}$ & $\begin{array}{l}1 \\
2 \\
3 \\
4 \\
5\end{array}$ & 10 & $\begin{array}{c}17.86 \\
17.875 \\
17.86 \\
17.86 \\
17.875\end{array}$ & $\begin{array}{l}1.786 \\
1.788 \\
1.786 \\
1.786 \\
1.788 \\
\end{array}$ & $\begin{array}{l}0.0010 \\
0.0010 \\
0.0010 \\
0.0010 \\
0.0010 \\
\end{array}$ \\
\hline $221,40 \mathrm{~g}$ & $\begin{array}{l}1 \\
2 \\
3 \\
4 \\
5\end{array}$ & 10 & $\begin{array}{c}17.86 \\
17.875 \\
17.86 \\
17.875 \\
17.875\end{array}$ & $\begin{array}{l}1.786 \\
1.788 \\
1.786 \\
1.788 \\
1.788\end{array}$ & $\begin{array}{l}0.0010 \\
0.0010 \\
0.0010 \\
0.0010 \\
0.0010\end{array}$ \\
\hline & d) $[s$ & $\begin{array}{c}164,199 \\
1.789 \\
0.0010 \\
\end{array}$ & $\begin{array}{c}192,979 \\
1.788 \\
0.0010 \\
\end{array}$ & $\begin{array}{c}201,469 \\
1,787 \\
0.0010\end{array}$ & $\begin{array}{l}21,409 \\
1.787 \\
.0010\end{array}$ \\
\hline
\end{tabular}

Figura 7 : Tela HTML das medições obtidas por meio do uso do primeiro experimento.

Conforme os dados da Figura 7, foi gerado o Gráfico 1 , que relaciona o tempo médio dos períodos com os valores das massas das esferas utilizadas. 


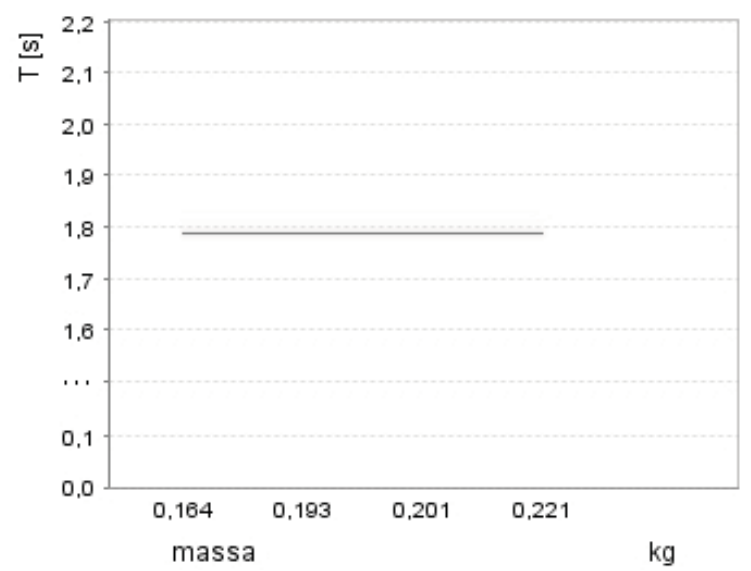

Gráfico 1 : Estudo da dependência do período das oscilações da massa do pêndulo.

Os resultados do primeiro experimento mostram que o período das oscilações do pêndulo não depende da sua massa.

Com base nos resultados do segundo experimento, foram geradas a Figura 8 e o Gráfico 2, relacionando o tempo médio dos períodos com os ângulos de amplitude.

Os dados obtidos a partir deste experimento mostram que o período não depende da amplitude das oscilações para ângulos menores ou iguais a 7 graus.

\begin{tabular}{|c|c|c|c|c|c|}
\hline \multirow{2}{*}{$\varphi[$ grau] } & \multicolumn{5}{|c|}{$I=0,785 \mathrm{~m} ; \mathrm{m}=164,19 \mathrm{~g}$} \\
\hline & \begin{tabular}{|l|} 
No. \\
\end{tabular} & No de oscilaçöes $n$ & Tempot $[s]$ & $T=t / n[s]$ & $\mathrm{BT}[s]$ \\
\hline \multirow{5}{*}{$4^{\circ}$} & 1 & & 17.813 & 1.781 & 0.0020 \\
\hline & 2 & & 17.828 & $\begin{array}{l}1.783 \\
1.783\end{array}$ & 0.0010 \\
\hline & 3 & 10 & 17.828 & 1.783 & 0.0010 \\
\hline & 4 & & 17.829 & 1.783 & 0.0010 \\
\hline & 5 & & 17.828 & 1.783 & 0.0010 \\
\hline \multirow{5}{*}{70} & 1 & & 17.859 & 1.786 & 0.0010 \\
\hline & 2 & & 17.844 & 1.784 & 0.0010 \\
\hline & 3 & 10 & 17.859 & 1.786 & 0.0010 \\
\hline & 4 & & 17.844 & 1.784 & 0.0010 \\
\hline & 5 & & 17.859 & $\begin{array}{l}1.786 \\
\end{array}$ & 0.0010 \\
\hline \multirow{5}{*}{$10^{\circ}$} & 1 & & 17.86 & 1.786 & 0.0010 \\
\hline & & & 17.859 & 1.786 & 0.0010 \\
\hline & 3 & 10 & 17.86 & 1.786 & 0.0010 \\
\hline & 4 & & 17.875 & 1.788 & 0.0010 \\
\hline & & & 17.875 & $\begin{array}{l}1.788 \\
1.788 \\
\end{array}$ & 0.0010 \\
\hline \multirow{4}{*}{$20^{\circ}$} & 1 & & 17.985 & 1.798 & 0.0020 \\
\hline & 2 & & 18.0 & 1.8 & 0.0010 \\
\hline & 3 & 10 & 17.968 & 1.797 & 0.0030 \\
\hline & $\begin{array}{l}4 \\
5\end{array}$ & & $\begin{array}{l}18.047 \\
18.016\end{array}$ & $\begin{array}{l}1.805 \\
1.802\end{array}$ & $\begin{array}{l}0.0050 \\
0.0020\end{array}$ \\
\hline \multirow{4}{*}{$30^{\circ}$} & 1 & & 18.156 & 1.816 & 0.0020 \\
\hline & 2 & & 18.14 & 1.814 & 0.0010 \\
\hline & 3 & 10 & 18.14 & 1.814 & 0.0010 \\
\hline & $\begin{array}{l}4 \\
5\end{array}$ & & $\begin{array}{l}18.125 \\
18.141\end{array}$ & $\begin{array}{l}1.812 \\
1.814\end{array}$ & $\begin{array}{l}0.0020 \\
0.0010\end{array}$ \\
\hline \multirow{4}{*}{$40^{\circ}$} & 1 & & 18.344 & 1.834 & 0.0010 \\
\hline & 2 & & 18.344 & 1.834 & 0.0010 \\
\hline & 3 & 10 & 18.344 & 1.834 & 0.0010 \\
\hline & 4 & & & 1.834 & 0.0010 \\
\hline & 5 & 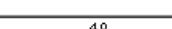 & $\frac{18.343}{100}$ & 1.834 & 0.0010 \\
\hline \multirow{2}{*}{\multicolumn{2}{|c|}{$\begin{array}{c}\text { }[\text { grau }] \\
T(\text { med) }[s] \\
\Delta T \text { (med) }[s]\end{array}$}} & 1.783 & $\begin{array}{c}100 \\
1.787\end{array}$ & 1.814 & $\begin{array}{c}40^{\circ} \\
1.834\end{array}$ \\
\hline & & 0.0010 & 0.0010 & 0.001 & 0.0010 \\
\hline
\end{tabular}

Figura 8 : Tela HTML dos resultados do segundo experimento.

A realização do terceiro experimento, possibilitou a obtenção dos resultados expressos na Figura 9.

Analiticamente, pode-se concluir que com $l>R$ a função $T=f(l)$ aproxima-se da função $T \sim \sqrt{l}$, característica para o período do pêndulo matemático. Para o estabelecimento experimental do tipo da função

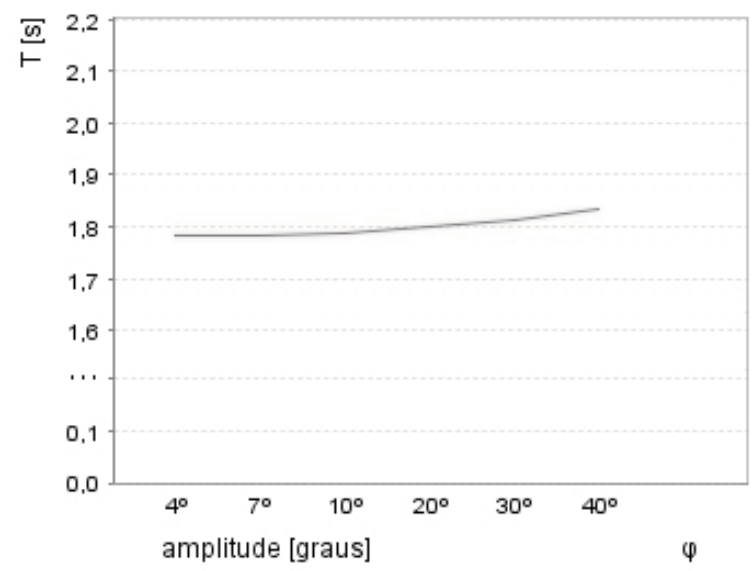

Gráfico 2 : Estudo da dependência do período da amplitude das oscilações.

$T=f(l)$ no campo de valores $l>R$, vamos supor que ela seja descrita por uma dependência exponencial da forma

$$
T=G l^{p},
$$

onde $G$ e $p$ são constantes. Tomando o logaritmo de (12), obtemos a seguinte expressão

$$
\log T=\log G+p \log l
$$

cuja representação gráfica é uma linha reta, mostrada no Gráfico 3.

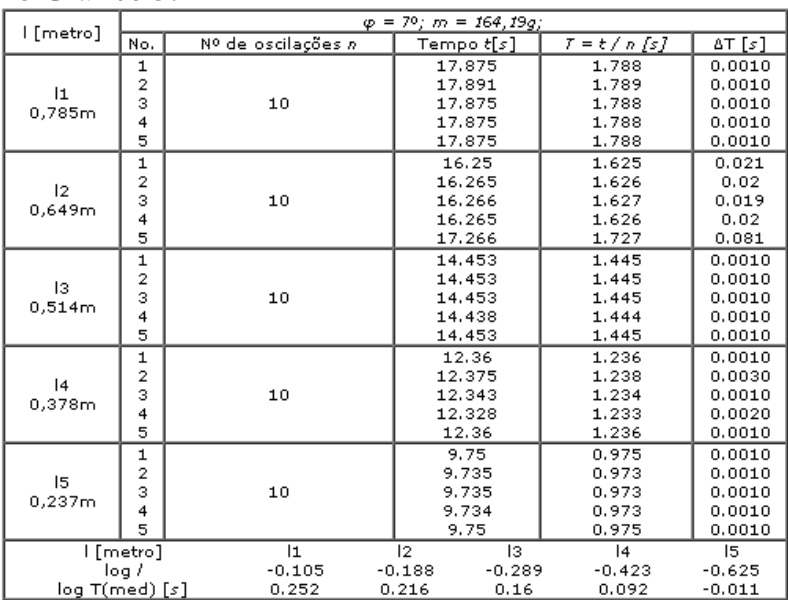

Figura 9 : Tela HTML dos resultados do terceiro experimento.

A tangente do ângulo de inclinação $\gamma$ desta linha com o eixo das abscissas determina o valor de $p$, e o seguimento do início das coordenadas ao ponto de intercessão do gráfico com o eixo das ordenadas determina o 
valor de $\log \mathrm{G}$. $\mathrm{O}$ valor teórico de $p$ é aproximadamente igual a $\frac{1}{2}$ e $G=\frac{2 \pi}{\sqrt{g}}$.

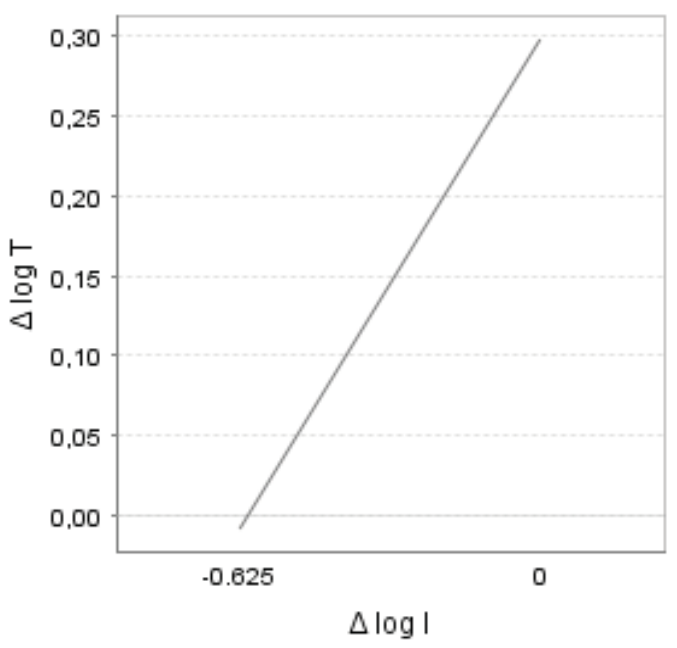

Gráfico 3 : Estudo da dependência do período, em relação ao comprimento da linha de suspensão.
Utilizando-se o Gráfico 3, foi obtido o valor de 0,488 para $p$ e, com o auxílio da regressão linear, aplicada ao referido gráfico, foi obtido o valor de 0,298 para o $\log G$. A partir deste valor, foi obtido o valor de $G$ igual a 1,986. Os resultados experimentais obtidos satisfazem as condições para que o pêndulo seja considerado pêndulo matemático.

Desta maneira, foi possível determinar, experimentalmente, a aceleração da força da gravidade, como expresso na Figura 10. Logo, a partir dos resultados gerados e apresentados na tabela abaixo, com base nos valores das cinco primeiras medições do terceiro experimento, o valor médio obtido de $g=9,682 \pm 0,003 \mathrm{~m} / \mathrm{s}^{2}$. O erro relativo de medição de $g$ foi de 0,014 .

\section{Considerações Finais}

No pêndulo matemático automatizado, manipulado remotamente, o computador é utilizado em todo o âmbito do experimento laboratorial, desde a coleta dos dados das medições até a elaboração dos resultados. Isto concede ao aluno mais tempo para uma melhor reflexão sobre os aspectos tecnológicos e metodológicos do experimento, e sua ligação com a teoria.

\begin{tabular}{|c|c|c|c|c|c|c|}
\hline m [g] & No & $\mathbf{n}^{\circ}$ de oscilações n & $t[s]$ & $T=t / n[s]$ & I [m] & $g\left[\mathrm{~m} / \mathrm{s}^{2}\right]$ \\
\hline $164,19 \mathrm{~g}$ & 1 & 10 & 17.875 & 1.788 & 0,785 & 9.694 \\
\hline $164,19 \mathrm{~g}$ & 2 & 10 & 17.891 & 1.789 & 0,785 & 9.683 \\
\hline $164,19 \mathrm{~g}$ & 3 & 10 & 17.875 & 1.788 & 0,785 & 9.694 \\
\hline $164,19 \mathrm{~g}$ & 4 & 10 & 17.875 & 1.788 & 0,785 & 9.694 \\
\hline $164,19 \mathrm{~g}$ & 5 & 10 & 17.875 & 1.788 & 0,785 & 9.694 \\
\hline & & & \multicolumn{3}{|c|}{$g[$ medio $]\left(\mathrm{m} / \mathrm{s}^{2}\right)$} & 9.692 \\
\hline & & & & \multicolumn{2}{|c|}{$\Delta g[$ medio $]\left(\mathrm{m} / \mathrm{s}^{2}\right)$} & 0.0030 \\
\hline & & & & \multicolumn{2}{|r|}{$g\left(\mathrm{~m} / \mathrm{s}^{2}\right)$} & $9.692 \pm 0.0030$ \\
\hline \multicolumn{7}{|c|}{ O erro relativo de medição da grandeza $g$ determinado pela fórmula: } \\
\hline \multicolumn{7}{|c|}{$\frac{\Delta g}{g}=\sqrt{4\left(\frac{\Delta \pi}{\pi}\right)^{2}+\left(\frac{\Delta l}{l}\right)^{2}+4\left(\frac{\Delta T_{0}}{T_{0}}\right)^{2}}$} \\
\hline
\end{tabular}

Figura 10 : Determinação da aceleração da força da gravidade.

Por meio dos resultados obtidos, foi possível realizar um estudo das oscilações do pêndulo, bem como das condições que definem o pêndulo matemático, podendo assim determinar o valor da aceleração da força da gravidade. Outro fator importante a ser levado em conta é a maior precisão das medições.

O pêndulo matemático automatizado apresenta diversas características importantes para a reutilização conceitual. Elas serão aplicadas nos demais experimentos do laboratório de mecânica.
Entretanto, vários trabalhos [1] sugerem que as preferências dos estudantes, e talvez seu desempenho de aprendizagem, não pode ser atribuído somente à tecnologia de laboratório. É preciso saber como as atividades mentais do aluno estão desenvolvidas no laboratório, então outros fatores como motivação, a colaboração dos pares, feedback corretiva de erros e a riqueza dos meios de comunicação devem ser considerados para produzir laboratórios mais interativos e imersivos.

Para tanto, consideramos necessário, nos trabalhos futuros, ampliar a prática laboratorial remota de estudo na base de desenvolvimento do laboratório híbrido para 
avaliar diferentes aspectos de aprendizagem com a ajuda de novos modelos, de novas abordagens de laboratório.

\subsection{Trabalhos Futuros}

Propõe-se, a partir deste trabalho, a integração com outros sistemas automatizados que o laboratório já disponibiliza, que possuem arquitetura semelhante ao sistema do pêndulo matemático.

A fim de proporcionar uma melhor qualidade da imagem do experimento em execução, é proposta a criação de um servidor de câmeras independente, com a utilização de mais câmeras por experimento, uma plataforma de desenvolvimento que possa oferecer melhor suporte ao stream, e também o uso de recursos que proporcionem a movimentação das câmeras.

Em continuidade ao trabalho realizado, propõe-se avaliar o impacto da utilização das novas ferramentas no ensino/aprendizagem dos alunos. Neste sentido [1], verifica-se que o surgimento de novos modelos de laboratório, o simulado e o remoto, como alternativas para os laboratórios tradicionais, está intrinsecamente ligado com as aplicações dos avanços da tecnologia da informação.

Contudo, ao lado dos laboratórios supra citados, podem ser acrescentados outros modelos de laboratórios didáticos de física: o laboratório que utiliza o método da vídeo-análise e o laboratório demonstrativo. Nesse sentido, o pêndulo matemático automatizado, manipulado remotameente, pode satizfazer o conceito de laboratório híbrido pela sua arquitetura.

No experimento remoto: 1) Uma câmera ou conjunto de câmeras e o circuito de sensores, que fazem parte da arquitetura, são conectados ao PC host, que é responsável pela captura e armazenamento dos dados e controle do experimento, podendo também armazenar as imagens capturadas; 2) A vídeo-análise pode ser utilizada através do posicionamento adequado das câmeras para capitar as imagens do experimento de vários ângulos; 3) Analogamente, pode-se utilizar o modelo do laboratório demonstrativo.

A vídeo-análise para fins educacionais consiste em fazer uma tomada de vídeo de um fenômeno ou experimento e depois executar uma análise minuciosa sobre este vídeo através de ferramentas que relacionem o fenômeno que se quer estudar com grandezas (observáveis) da Física e suas quantificações.[19].

Pretende-se, assim, enumerar as diversas vantagens do experimento automatizado, na base do estudo do pêndulo matemático, desenvolvido na forma de laboratório híbrido, onde são integrados, na mesma maquete, diversos modelos do experimento. Desta forma [1], pode-se enriquecer o currículo dos cursos. Pode-se, também, desta maneira, através da reutilização do experimento automatizado ( laboratórios híbridos), fazer o estudo comparativo dos mesmos.

Segundo Gravier et.al [2], os laboratórios remotos estão sofrendo uma grande evolução, mas o grande número de tecnologias utilizadas para o seu desenvolvimento indica que pouco esforço está sendo impregado para reutilizar os laboratórios remotos existentes.

Para cada etapa do desenvolvimento, existem varias opções de tecnologias. A escolha de algumas delas é inerente ao tipo de experimento, mas geralmente é baseada em experiência anterior, infraestrutura e ferramentas de desenvolvimento disponíveis, habilidades e experiência dos desenvolvedores.

\section{Referências}

[1] J. Ma, \& J.V. Nickerson. Hands-On, Simulated, and Remote Laboratories: A Comparative Literature Review. ACM Computing Surveys. 38(3), 7-es. doi:10.1145/1132960.1132961, 2006.

[2] C.Gravier, J. Fayolle, B. Bayard, M. Ates, J. Lardon. State of the art about remote laboratories paradigms - foundations of ongoing mutations. International Journal of Online Engineering. 1, 1-9, 2008.

[3] X. Chen, G. Song, Y. Zhang. Virtual and Remote Laboratory Development: A Review. Earth and Space 2010: Engineering, Science, Construction, and Operations in Challenging Environments, 368-368. Asce. doi:10.1061/41096(366)368. 2010.

[4] M. Domínguez, J. J. Fuertes, M. A. Prada, S. Alonso, A. Morán. Remote laboratory of a quadruple tank process for learning in control engineering using different industrial controllers. Computer Applications in Engineering Education, n/a-n/a. doi:10.1002/cae.20562. 2011.

[5] M. T. Chella. Arquitetura para laboratório de acesso remoto com aplicações educacionais. Tese (doutorado) - Universidade Estadual de Campinas, Faculdade de Engenharia Elétrica e de Computação, Jul 2006.

[6] O. Toader, V.H. Rotberg, G.S. Was. Remote Monitoring and Control of Irradiation Experiments. Application of Accelerators in Research and Industry: 17TH International Conference on the Application of Accelerators in Research and Industry. 2003.

[7] A. C. Ammari, J. B. H. Slama. THE DEVELOPMENT OF A REMOTE LABORATORY FOR INTERNET-BASED ENGINEERING 
EDUCATION. Journal of Asynchronous Learning, 3-13. 2006

[8] D. Karadimas, K. Efstathiou, K. An Integrated Educational Platform Implementing Real, Remote Lab-Experiments for Electrical Engineering Courses. Journal of Computers, 2(2), 37-44. doi:10.4304/jcp.2.2.37-44. 2007.

[9] G. Andria, A. Baccigalupi, M. Borsic, S. Member, P. Carbone, A. Member, P. Daponte, et al. Remote Didactic Laboratory "G . Savastano" The Italian Experience for ELearning at the Technical Universities in the Field of Electrical and Electronic Measurements : Overview on Didactic Experiments. IEEE Transactions on Instrumentation and Measurement, 56(4), 1135 1147. 2007.

[10] E. Irmak, R. Bayindir, I. Colak, M. Soysal, M. A remote laboratory experiment for 4-quadrant control of a DC motor. Computer Applications in Engineering Education, 19(4), 747-758. doi:10.1002/cae.20361. 2009.

[11] C. R. S. Oliveira, I.N. Oliveira, A.L. Pereira, H.L. Santos. Um Ambiente para a Prática Remota de Aulas Laboratoriais de Física (determinação da viscosidade de líquidos). Revista Brasileira de Informática na Educação, Volume 17, Número 1. 2009.

[12] A. Tekin, F. Ata, M. Gökbulut. Remote control laboratory for DSP-controlled induction motor drives. Computer Applications in Engineering Education, n/a-n/a. doi:10.1002/cae.20440. 2010.

[13] C. Lucio, \& N. Junior. Acionamento de motores para o $\pi$ bot - Pêndulo Invertido Robotizado Weblab sobre rede KyaTera Experimentos de robótica móvel. 2009.

[14] J. E. Corter, S. K. Esche, C. Chassapis, J. Ma, J. V. Nickerson. Process and learning outcomes from remotely-operated, simulated, and handson student laboratories. Computers \& Education, 57(3),2054-2067. doi:10.1016/j.compedu.2011.04.009. 2011.

[15] J. Lang. Comparative Study of Hands-on and Remote Physics Labs for First Year University Level Physics Students. Transformative Dialogues: Teaching \& Learning Journal, 6(1), 1-25. 2012.

[16] I. N. Oliveira. Estudo do Pêndulo Matemático e Determinação da Aceleração da Força da Gravidade com a sua Ajuda: Trabalho de Laboratório $\mathrm{N}^{\mathrm{o}}$ 2. Universidade Estadual do Sudoeste da
Bahia, publicação interna, 2000.

[17] A. R. Messias. Introdução à Porta Paralela. 2006.Disponívelem:<http://www.rogercom.com/ pparalela/introducao.htm>. Acesso em: 07 maio 2010.

[18] A. S. M. Trentim, et al. A utilização de laboratórios virtuais na Melhoria do Processo de EnsinoAprendizagem. Universidade de Passo Fundo, Instituto de Ciências Exatas e Geociências Ciência da Computação, 2002, 8 páginas.

[19] L. I. Leitão, F.P.D. Teixeira, F.S. Rocha. A vídeo-análise como recurso voltado ao ensino de física experimental: um exemplo de aplicação na mecânica. Revista Eletrónica de Investigacion en Ciencias, v. 6, No. 1, pp. 1-15. 2011. 